\title{
Reovirus-induced apoptosis requires both death receptor- and mitochondrial-mediated caspase-dependent pathways of cell death
}

\author{
DJ Kominsky ${ }^{1}$, RJ Bickel ${ }^{1}$, and KL Tyler ${ }^{\star, 1,2,3}$ \\ ${ }^{1}$ Department of Neurology, University of Colorado Health Science Center, \\ Denver, Colorado 80262, USA \\ 2 Department of Medicine, Microbiology, and Immunology, University of \\ Colorado Health Science Center, Denver, Colorado 80262, USA \\ ${ }^{3}$ Denver Veteran's Affairs Medical Center, Denver, Colorado 80220, USA \\ * Corresponding author: KL Tyler, Department of Neurology (B-182), University \\ of Colorado Health Science Center, 4200 E. 9th Avenue, Denver, CO 80262 , \\ USA. Tel: (303) 393-2874; Fax: (303) 393-4686; \\ E-mail: Ken.Tyler@uchsc.edu.
}

Received 17.10.01; revised 14.1.02; accepted 6.2.02

Edited by CJ Thiele

\begin{abstract}
Apoptosis plays an important role in the pathogenesis of many viral infections. Despite this fact, the apoptotic pathways triggered during viral infections are incompletely understood. We now provide the first detailed characterization of the pattern of caspase activation following infection with a cytoplasmically replicating RNA virus. Reovirus infection of HEK293 cells results in the activation of caspase-8 followed by cleavage of the pro-apoptotic protein Bid. This initiates the activation of the mitochondrial apoptotic pathway leading to release of cytochrome $c$ and activation of caspase-9. Combined activation of death receptor and mitochondrial pathways results in downstream activation of effector caspases including caspase- 3 and caspase- 7 and cleavage of cellular substrates including PARP. Apoptosis is initiated by death receptor pathways but requires mitochondrial amplification producing a biphasic pattern of caspase-8, Bid, and caspase- 3 activation.

Cell Death and Differentiation (2002) 9, 926-933. doi:10.1038/ sj.cdd. 4401045
\end{abstract}

Keywords: apoptosis; reovirus; caspase; death receptor; mitochondria

Abbreviations: JAM, junction adhesion molecule; TNF, tumor necrosis factor; TRAIL, TNF-related apoptosis-inducing ligand; DR, death receptor; DISC, death-inducing signaling complex; FADD, Fas-associated death domain; DEVD-AFC, Asp-Glu-Val-Asp-7amino-4-methyl coumarin; PARP, poly(ADP-ribose) polymerase; Ac-YVAD-CHO, Ac-Tyr-Val-Ala-Asp-CHO; Ac-DEVD-CHO, AcAsp-Glu-Val-Asp-CHO; Ac-IETD-CHO, Ac-lle-Asp-Thr-Glu-CHO

\section{Introduction}

Apoptosis is a particular type of cell death that is characterized by distinctive changes in cellular morphology, including cell shrinkage, zeiosis, nuclear condensation, chromatin margination and subsequent degradation that are associated with inter-nucleosomal DNA fragmentation. Apoptosis may be initiated by a wide variety of cellular insults, including death receptor stimulation, $\gamma$-radiation, and cytotoxic compounds. Induction or inhibition of apoptosis is an important feature of many types of viral infection, both in vitro and in vivo. Despite this fact, the mechanisms of virus-induced apoptosis remain largely unknown. This is particularly true for RNA viruses, the majority of which have cytoplasmic intracellular sites of replication and do not require nuclear integrity for successful propogation.

Mammalian reoviruses are non-enveloped doublestranded RNA viruses whose replication occurs exclusively in the cytoplasm. Reoviruses induce apoptosis in a wide variety of cultured cells in vitro. ${ }^{1-3}$ Apoptosis also plays a critical role during reovirus infection in vivo, and is the mechanism of virus-induced tissue injury in key target organs, including the central nervous system and heart. ${ }^{1,4,5}$ Inhibition of apoptosis dramatically reduces the extent of reovirus-induced tissue injury in vivo. ${ }^{5}$

It has been shown recently that reovirus-induced apoptosis requires interaction with its cell surface receptors including junction adhesion molecule (JAM). ${ }^{6}$ Apoptosis involves the tumor necrosis factor (TNF) superfamily of cell surface death receptors, specifically DR4, DR5 and their ligand, TNF-related apoptosis-inducing ligand (TRAIL), ${ }^{7}$ and is inhibited by anti-TRAIL antibodies or soluble forms of DR4 or DR5 which inhibit interaction of TRAIL with functional cell surface DR4 and DR5. ${ }^{7}$ The contribution of mitochondrial apoptotic pathways to this process has been unknown, as has the exact nature of the caspase cascades activated and their inter-relationship.

Apoptosis induced by activation of cell surface death receptors ('extrinsic pathway') involves the formation of a death-induced signaling complex (DISC) that recruits and activates caspase- $8 .{ }^{8}$ Activated caspase- 8 can, in turn, activate downstream effector caspases including caspases3 and -7 . Mitochondria play a central role in an 'intrinsic' pathway of apoptosis. In this pathway, apoptotic stimuli enhance mitochondrial membrane permeability and permit the translocation of cytochrome $c$ and other pro-apoptotic molecules from the mitochondria into the cytosol. ${ }^{9-12} \mathrm{~A}$ cytosolic complex including cytochrome $c$ and Apaf-1 (apoptosome) activates caspase-9. ${ }^{13}$ Activated caspase-9, like activated caspase-8, can activate additional downstream effector caspases including caspase-3. The intrinsic and extrinsic pathways are linked by Bid, a pro-apoptotic 
Bcl-2 family member. Caspase-8-dependent cleavage of Bid allows this protein to translocate to the mitochondrion, where it directly or indirectly facilitates cytochrome $c$ release. ${ }^{14-18}$ The importance of the mitochondrial apoptotic pathway in augmenting death-receptor initiated apoptosis can be assessed by studying the pattern of caspase activation and the effects of $\mathrm{Bcl}-2$ expression. Death receptor-initiated, mitochondrial-dependent apoptosis is generally associated with early low level activation of caspase- 8 and is inhibitable by $\mathrm{Bcl}-2 .{ }^{19,20}$ Conversely, mitochondrial-independent, death receptor-initiated apoptosis is associated with more robust caspase- 8 activation and is not inhibited by $\mathrm{Bcl}-2$ expression. ${ }^{19,20}$

In this paper we provide the first comprehensive characterization of the pattern of caspase activation following infection with a cytoplasmically replicating RNA virus. We show that reovirus infection results in the activation of death receptor- and mitochondrial-associated initiator caspases, caspase- 8 and caspase-9. Activation of these initiator caspases is followed by activation of the effector caspases caspase-3 and caspase-7. Caspase-8dependent cleavage of the Bid provides a linkage between the death receptor and mitochondrial pathways of apoptosis following reovirus infection. Inhibition of caspase-8 activation prevents the cleavage of Bid, and the subsequent activation of the mitochondrial pathway. Both the mitochondrial and death receptor-initiated pathways are essential for reovirus-induced apoptosis as inhibition of death receptor pathways by over-expression of dominant negative FADD (FADD-DN) or of mitochondrial pathways by over-expression of $\mathrm{Bcl}-2$ prevents reovirus-induced effector caspase activation. Consistent with this model, cell permeable inhibitors of both group II caspases (caspase-2, -3, and 7) and group III caspases (caspase-6, -8, and -9) but not of group I caspases (caspase-1, -4, and -5) inhibit reovirusinduced caspase- 3 activation. These studies provide not only a comprehensive profile of caspase activation following virus infection, but also the first demonstration that both death receptor and mitochondrial pathways can play an essential role in virus-induced apoptosis.

\section{Results}

\section{Caspase- 8 is activated following reovirus infection}

Apoptosis initiated via TNF receptor superfamily cell death receptors involves the adaptor molecule FADD and subsequent activation of caspases, starting with the initiator caspase, caspase-8. ${ }^{21}$ We therefore wanted to examine whether reovirus infection induced the activation of caspase8. As shown in Figure 1a, reovirus infection induces the activation of caspase- 8 as evidenced by the disappearance of the full-length proenzyme (seen as a 55/54 kD doublet). The reduction in caspase- 8 immunoreactivity appeared to be biphasic. A first phase of activation was detectable as early as $8 \mathrm{~h}$ post-infection. A second, more intense phase of activation began at $22 \mathrm{~h}$ post-infection and continued through $\geqslant 34 \mathrm{~h}$ (Figure 1a,b). No cellular morphological changes were observed correlating with the early phase of caspase-8 activation.
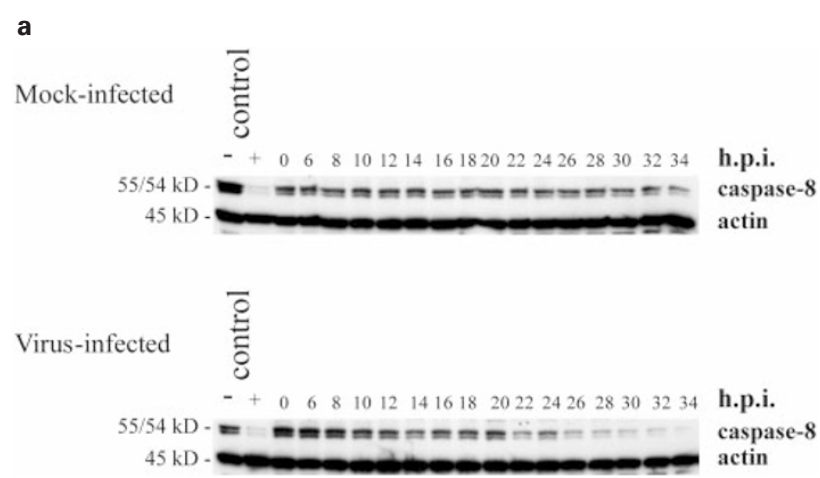

b

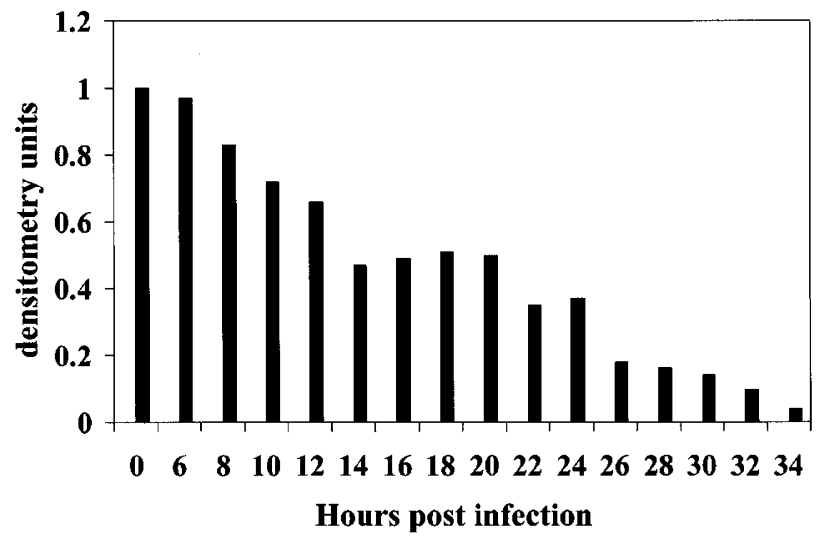

Figure 1 Reovirus infection induces the activation of caspase-8. HEK 293 lysates were prepared at the indicated times points from mock-infected or reovirus-infected cells and probed with anti-caspase- 8 antibodies and antiactin antibodies (a). Control lanes represent Jurkat cell lysates untreated $(-)$ or treated $(+)$ with activating anti-Fas antibody and harvested at $8 \mathrm{~h}$ post treatment. The Western is representative of two separate experiments. The graph displays densitometric analysis of the virus-infected Western blot analysis (b). Values are expressed as arbitrary densitometric units

\section{Reovirus infection is associated with release of mitochondrial cytochrome $c$ and activation of caspase-9}

Reovirus-induced activation of caspase-8 revealed a biphasic pattern. This suggested that apoptosis signals initiated through the death receptor pathway might be amplified by other apoptotic pathways. We therefore looked for evidence that reovirus infection activated mitochondrial-associated apoptotic signaling pathways. We first wished to determine whether reovirus infection was associated with release of cytochrome $c$ and activation of caspase-9. Mitochondria-free lysates were prepared from both mock- and reovirus-infected cells at the indicated time points and analyzed by Western blot for the presence of cytosolic cytochrome $c$ (Figure 2). Blots were probed with antisera directed against the mitochondrial integral membrane protein cytochrome $c$ oxidase (subunit II) to detect potential mitochondrial contamination of the samples. Cytosolic cytochrome $c$ is detected in reovirusinfected cells at $\sim 10 \mathrm{~h}$ post-infection (Figure $2 \mathrm{a}$ ). In order to determine whether cytochrome $c$ release was dependent on death receptor-initiated signaling, we also examined the 
cellular localization of mitochondrial cytochrome $c$ following reovirus infection in FADD-DN expressing cells. As shown in Figure $2 b$, cytochrome $c$ is found at only trace levels in the cytoplasm of reovirus-infected FADD-DN expressing cells. These results indicate that caspase- 8 activation occurs upstream of, and is required for, the release of cytochrome c. We next wished to determine whether caspase-9 was activated. Activation of caspase- 9 involves the cleavage of the $46 \mathrm{kD}$ pro-enzyme into a $37 \mathrm{kD}$ active fragment. Activated caspase- 9 was first detectable in reovirus-infected cells at $10 \mathrm{~h}$ post-infection (Figure 3), and was not detected in mockinfected cells. Activation increased steadily from 10 to $18 \mathrm{~h}$ and then persisted for $\geqslant 32 \mathrm{~h}$.

a
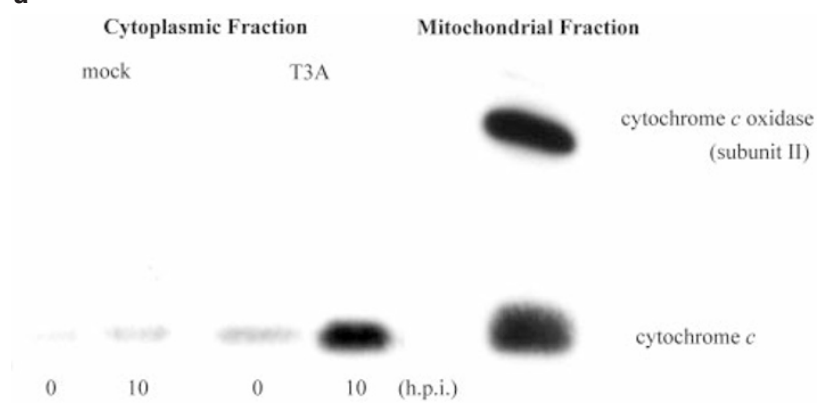

b
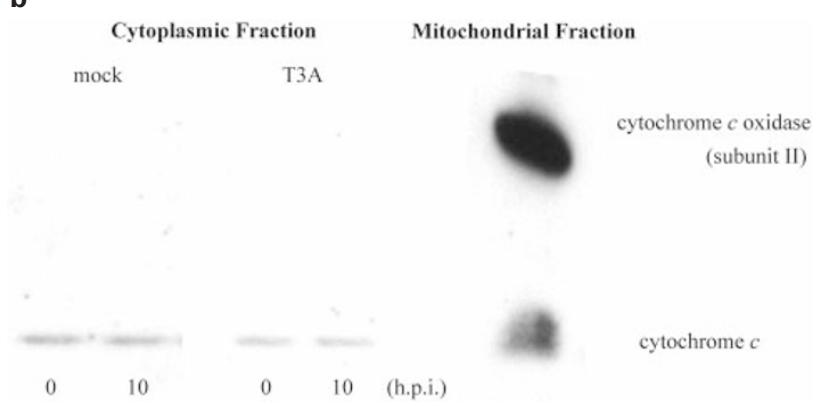

Figure 2 Cytochrome $c$ is present in the cytosol of reovirus infected cells. HEK 293 cell lysates (a) and FADD-DN expressing HEK 293 cells lysates (b) were prepared at the indicated time points as described (see Materials and Methods) and resolved using SDS-PAGE. Western blot analysis was performed using anti-cytochrome $c$ antibodies and anti-cytochrome $c$ oxidase (subunit II) and are representative of three separate experiments

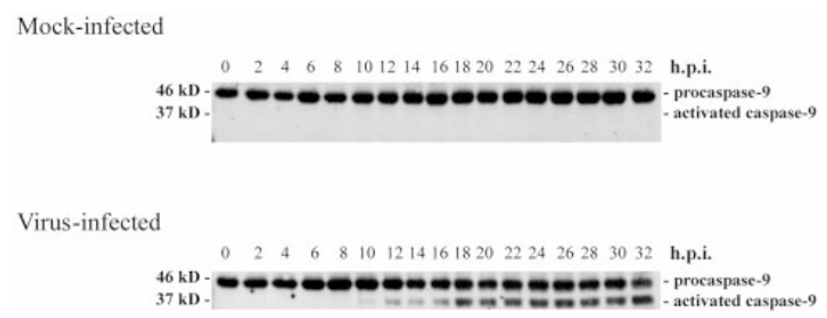

Figure 3 Caspase- 9 is activated in reovirus-infected cells. HEK 293 cell lysates were prepared from mock-infected or reovirus-infected cells at the indicated time points and resolved by SDS -PAGE. Western blot analysis was performed using anti-caspase- 9 antibodies and the blot is representative of three separate experiments

\section{Bid is cleaved following reovirus infection}

Bid is a pro-apoptotic member of the $\mathrm{Bcl}-2$ protein family. Activation of both Fas receptor by Fas and DR4/DR5 by TRAIL can induce caspase-8 dependent cleavage of Bid. ${ }^{15,17,18}$ Cleaved Bid can facilitate the release of cytochrome $c$ from the mitochondrion and lead to subsequent apoptosome-mediated activation of caspase-9. ${ }^{16}$ We wished to determine whether Bid was cleaved following reovirus infection, and if this cleavage depended on caspase-8 activation. Western blot analysis revealed that full-length Bid levels remain relatively unchanged in mock-infected cells (Figure 4a). However, following reovirus infection there was a biphasic pattern of Bid cleavage, analogous to that seen with caspase-8 (Figure 4a). Loss of the full length immunoreactive Bid was first detected as early as $10 \mathrm{~h}$ post-infection. A second phase of Bid cleavage began at $26 \mathrm{~h}$ post-infection and continued through $\geqslant 40 \mathrm{~h}$ (Figure $4 \mathrm{a}, \mathrm{b}$ ). In order to determine whether Bid cleavage was dependent on caspase8 activation, we examined levels of immunoreactive Bid in cells in which caspase-8 activation was blocked by stable expression of DN-FADD. FADD-DN expression completely inhibited reovirus-induced Bid cleavage, indicating that Bid cleavage is caspase-8 dependent (Figure 4c).

\section{Reovirus infection is associated with activation of caspase- 3 and caspase-7}

Effector caspases, including caspases-3, -6 and -7 , form part of the final common pathway for death receptor and mitochondrial apoptotic pathways. Having shown that reovirus infection resulted in activation of both death receptor and mitochondrion-associated initiator caspases we next wished to determine which effector caspases were activated. Caspase-3 activation was evaluated by Western blot, using an antibody specific for the activated form of the enzyme. Activation of caspase- 3 is associated with the appearance of specific cleavage product at $\sim 20 \mathrm{kD}$ representing the large subunit of active caspase-3. As shown in Figure $5 \mathrm{a}$, this fragment appears beginning at $\sim 8 \mathrm{~h}$ post-infection in reovirus infected cells, but not in the mock infected controls. There is a biphasic activation profile, with the initial activation phase beginning at $8 \mathrm{~h}$ post-infection and a second, more intense activation phase beginning at $24 \mathrm{~h}$ post-infection (Figure $5 \mathrm{a}$ ). A similar pattern of caspase activation was seen in fluorogenic substrate assays using a caspase-3 specific substrate (DEVD-AFC) (see Figure 6c). An initial phase of activation at $6-12 \mathrm{~h}$ was followed by a rapid activation peak $12-18 \mathrm{~h}$. Activated caspase- 3 cleaves a variety of cellular substrates to induce the morphological hallmarks of apoptosis. We therefore examined the cleavage of PARP. PARP is cleaved by caspase-3 from the full-length $116 \mathrm{kD}$ protein to an $85 \mathrm{kD}$ inactive fragment. As shown in Figure 5b, PARP cleavage exceeding that seen in mock-infected cells was first detectable at $14 \mathrm{~h}$ post-infection and persisted until $\geqslant 20 \mathrm{~h}$ post-infection. These experiments established that reovirus infection results in activation of the effector caspase, caspase- 3 and is associated with cleavage of cellular substrates of caspase-3.

Other effector caspases may also be activated downstream of caspase-8 and caspase-9. Therefore, we 
Mock-infected BID

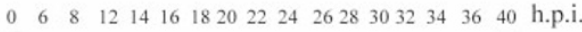

Actin

Virus-infected

BID

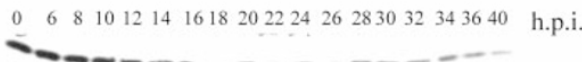

Actin

b

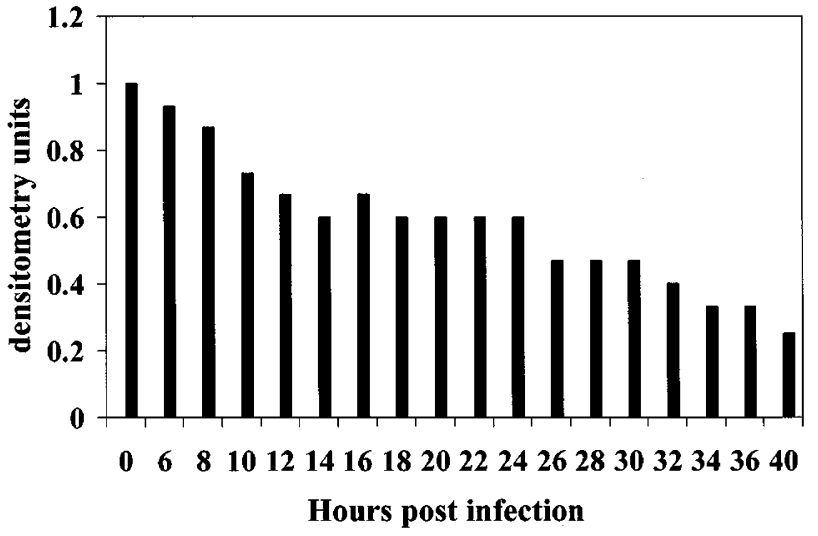

C

BID

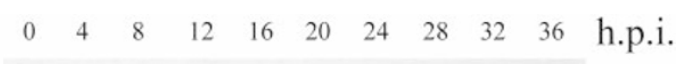

Actin

Figure 4 Reovirus infection leads to cleavage of full-length Bid. Lysates were prepared at the indicated time points from mock-infected or reovirus-infected HEK 293 cells (a) and reovirus infected FADD-DN expressing HEK 293 cells (c) and probed with anti-Bid antibodies and anti-actin antibodies. Each Western blot is representative of two separate experiments. The graph displays densitometric analysis of the virus-infected Western blot analysis (b). Values are expressed as arbitrary densitometric units

examined the activation state of two other effector caspases, caspase- 6 and caspase-7. We found no evidence by immunoblot of caspase- 6 activation in reovirus-infected cells (data not shown). Caspase-7 is activated in infected cells as evidenced by the detection of the $20 \mathrm{kD}$ large subunit of active caspase-7 (Figure $5 \mathrm{C}$ ). However, caspase-7 activation appears to occur later than activation of caspase-3, and the amount of activation appears less. a

Mock-infected

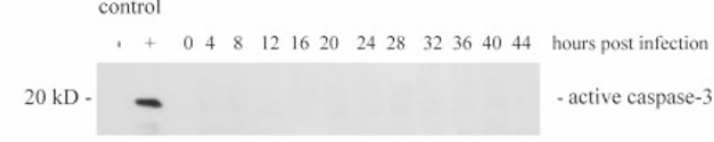

Virus-infected

control

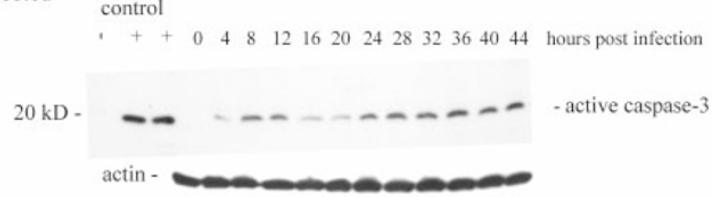

b

Mock-infected

$\begin{array}{llllllllllll}0 & 2 & 4 & 6 & 8 & 10 & 12 & 14 & 16 & 18 & 20 & \text { h.p.i. }\end{array}$

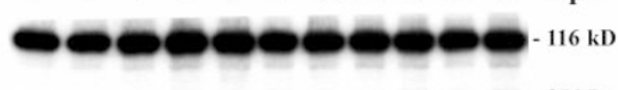

Virus-infected

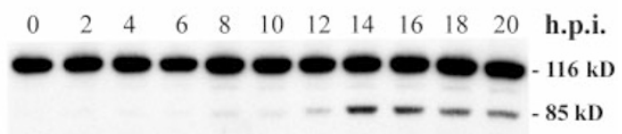

c

Mock-infected

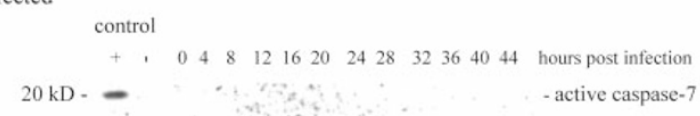

Virus-infected

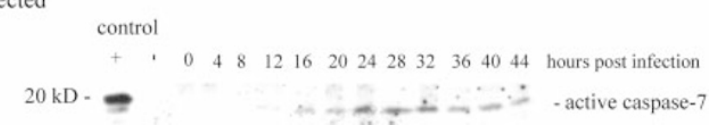

Figure 5 Reovirus infection leads to activation of caspase-3. Western blot analysis was performed using HEK 293 lysates harvested at the indicated time points from mock-infected and reovirus-infected cells and probed with anticaspase-3 antibodies (a), anti-PARP antibodies (b), or anti-caspase-7 antibodies (c). Control lanes represent Jurkat cell lysates untreated $(-)$ or treated (+) with activating anti-Fas antibody and harvested at $8 \mathrm{~h}$ post treatment. Each Western is representative of two separate experiments

In order to determine whether activation of effector caspases was completely dependent on the initial activation of death-receptor mediated pathways, we examined effector caspase activation in cells stably expressing DNFADD. As shown in Figure $6 a$, the activation of both caspase-3 and caspase-7 is blocked in cells stably expressing DN-FADD. Caspase-3 activity, as measured in a fluorogenic substrate assay, is almost completely inhibited in these cells (Figure 6c). This suggests that activation of death-receptor initiated apoptotic signaling pathways is required for reovirus-induced effector caspase activation and apoptosis. 
control

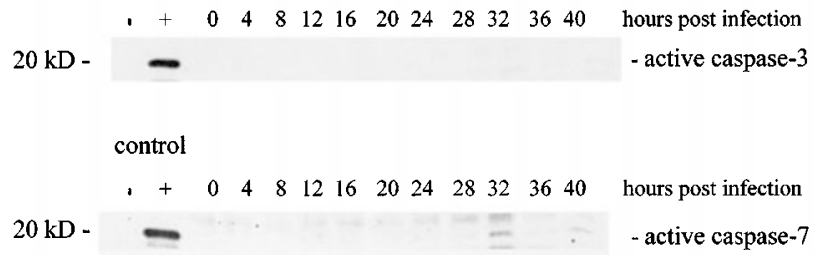

b

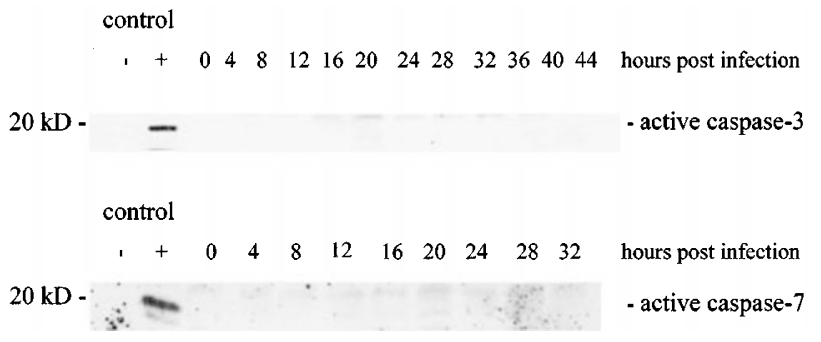

C

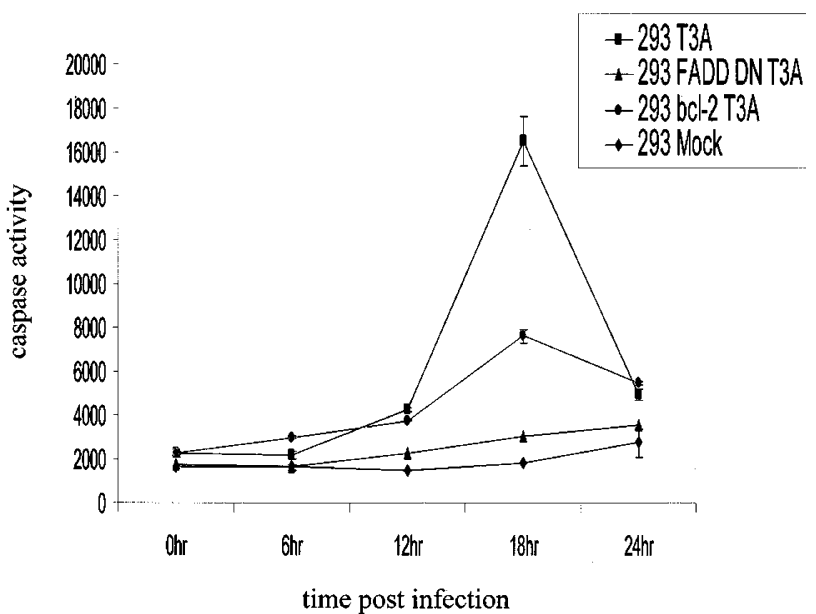

Figure 6 Effector caspase activation in inhibited in FADD-DN and Bcl-2 overexpressing cells. Western blot analysis was performed using cell lysates prepared from reovirus-infected FADD-DN over-expressing cells (a) or Bcl-2 overexpressing cells (b) at the indicated time points and probed with anticaspase-3 antibodies and anti-caspase-7 antibodies. Control lanes represen Jurkat cell lysates untreated $(-)$ or treated $(+)$ with activating anti-Fas antibody and harvested at $8 \mathrm{~h}$ post treatment. Western blots are representative of two separate experiments. Fluorogenic substrate assays (c) were performed in triplicate. Error bars represent standard error of the mean. Fluorescence is expressed as arbitrary units

\section{Bcl-2 overexpression inhibits effector caspase activation following reovirus infection}

Experiments with FADD-DN indicated that death-receptor pathways were necessary for reovirus-induced apoptosis. Activation of both caspase-8 and Bid showed a biphasic pattern with an early activation phase at $8-10 \mathrm{~h}$ followed by a later activation phase. Reovirus-induced initiation of mitochondrial apoptotic pathways occurred downstream of caspase-8 activation, began slightly later following infection, and was not biphasic. This suggested that mitochondrial apoptotic pathways might play a central role in amplifying death receptor-initiated signaling. The capacity of $\mathrm{Bcl}-2$ to inhibit apoptosis has been used as evidence suggesting an essential role for mitochondrial apoptotic pathways. ${ }^{19,20} \mathrm{We}$ wished to determine whether $\mathrm{Bcl}-2$ over-expression in HEK cells inhibited caspase activation. Caspase activation was examined using both Western blot analysis and fluorogenic substrate assays. As shown in Figure $6 \mathrm{~b}$, activation of both caspase- 3 and caspase- 7 is inhibited in cells over-expressing $\mathrm{Bcl}-2$. The late phase of caspase-8 activation was also inhibited in these cells although the low level early phase of caspase-8 activation was preserved (data not shown). Caspase-3 activity, as measured in a fluorogenic substrate assay, is also significantly reduced in these cells (Figure 6c). However, the pattern of inhibition differs from that seen in cells stably expressing DN-FADD. In Bcl-2 expressing cells there is some residual caspase-3 activation suggesting that death receptor-mediated apoptotic pathways can induce low levels of effector caspase activation, but full induction requires augmentation by mitochondrial apoptotic pathways. This low level of caspase-3 activation in Bcl-2 overexpressing cells was not reflected in cellular morphology.

\section{Effects of synthetic caspase peptide inhibitors on caspase- 3 activation}

Caspases can be categorized into three major groups based on their pattern of substrate specificity. ${ }^{22,23}$ Group I includes caspase-1, -4, and 5; group II includes caspase-2, -3 , and 7; group III includes caspase- $6,-8$ and -9 . Cell permeable, reversible, peptide caspase inhibitors have been developed based on these caspase substrate profiles. ${ }^{22,23}$ We tested the capacity of three reversible cell permeable caspase inhibitors with specificity for group I (Ac-YVAD-CHO), group II (AcDEVD-CHO), and group III (Ac-IETD-CHO) caspases to inhibit reovirus-induced caspase- 3 activation at $18 \mathrm{~h}$ postinfection. As shown in Figure 7, the group II inhibitor AcDEVD-CHO completely inhibited reovirus-induced caspase-3 activity at a concentration of $10 \mu \mathrm{M}$. The group I inhibitor (AcYVAD-CHO) had no effect on caspase-3 activation, consistent with a lack of involvement of caspases-1, -4 or -5 in reovirus-induced apoptosis. The group III inhibitor Ac-IETD$\mathrm{CHO}$ achieved maximal inhibition of reovirus-induced caspase-3 activation at a concentration of $5 \mu \mathrm{M}$. However, the maximum degree of inhibition (65\%) was not as high as that seen with the group II inhibitor. These data suggest that while the activation of group III caspases, including caspase-8 and 9 , is critically important to reovirus-induced apoptosis that other as yet unidentified caspases may also contribute to caspase-3 activation. However, the fact that expression of DN-FADD was as effective as treatment with the group II inhibitor Ac-DEVD-CHO in blocking caspase-3 activation, suggests that the apical caspases that contribute to caspase3 activation all depend on an initial death-receptor initiated caspase activation signal.

\section{Discussion}

Understanding the mechanisms of virus-induced apoptosis is crucial to understanding how viruses injure target tissues and 


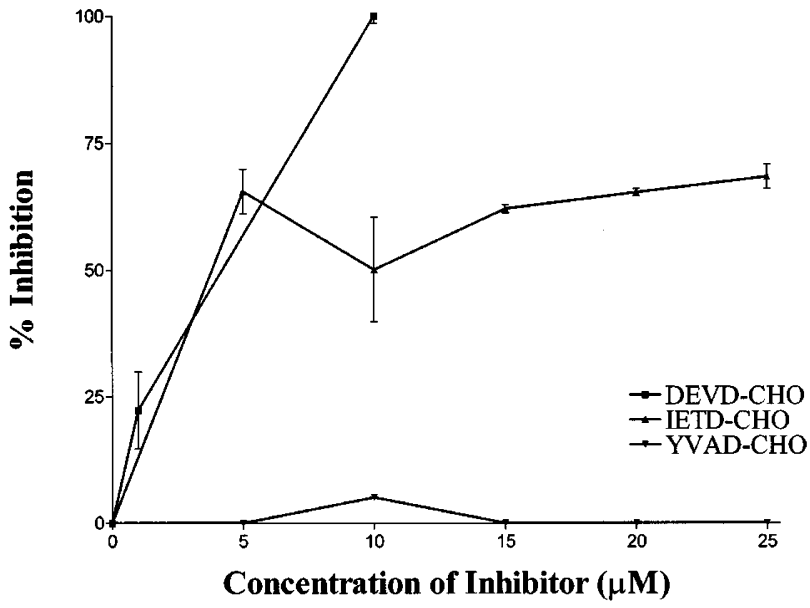

Figure 7 Synthetic peptide inhibition of DEVD-specific caspase activation. HEK 293 cells were pretreated with the synthetic peptide inhibitors at the concentrations shown for $1 \mathrm{~h}$ prior to reovirus infection (M.O.I. 100). Fluorogenic substrate assays were performed at $18 \mathrm{~h}$ post infection. Values are expressed as per cent inhibition where untreated reovirus-infected cells represent $0 \%$ inhibition and mock-infected cells represent 100\% inhibition

induce disease. The exact pathways leading to virus-induced apoptosis are still incompletely understood. Since caspases play a central role in virtually all known apoptotic signaling pathways, it is not surprising that they have been implicated in virus-induced apoptosis. Pancaspase peptide inhibitors have been shown to inhibit apoptosis induced by viruses as diverse as Sindbis, ${ }^{24,25} \mathrm{HIV}-1,{ }^{26,27}$ Herpes simplex virus type $1,{ }^{28}$ influenza, ${ }^{29}$ Sendai, ${ }^{30}$ and TGEV. ${ }^{31}$

The events that initiate caspase activation in virusinfected cells are still incompletely understood. Activation of caspase-8 plays an important role in apoptosis induced by HIV-1, ${ }^{26}$ influenza, ${ }^{29}$ Sendai, ${ }^{30}$ and Sindbis, ${ }^{24}$ suggesting that death-receptor initiated processes may be important in apoptosis induced by these viruses.

Many forms of virus-induced apoptosis are inhibited by anti-apoptotic members of the Bcl-2 family. ${ }^{32-35}$ One of the most thoroughly investigated mechanisms for the antiapoptotic actions of $\mathrm{Bcl}-2$ involves its inhibition of the release of cytochrome $c$ from mitochondria. ${ }^{36,37}$ Abnormalities of mitochondrial transmembrane potential and release of cytochrome $c$ have been described following infection with HIV, ${ }^{38}$ TGEV $^{31}$ chicken anemia virus, ${ }^{39}$ and herpes simplex virus. ${ }^{28}$ These studies suggest that both mitochondrial and death-receptor mediated pathways may play an important role in virus-induced apoptosis.

Reovirus-induced apoptosis involves the DR4/DR5/ TRAIL system of cell surface death receptors. ${ }^{7}$ In this study we found that caspase- 8 was activated within $8 \mathrm{~h}$ of reovirus infection. The activation of caspase- 8 occurs in two distinct phases, consistent with a model in which initial death-receptor mediated activation of caspase-8 is subsequently augmented by activation of caspase- 9 or other caspases (discussed below). Following activation, caspase8 cleaves Bid, a pro-apoptotic Bcl-2 family protein. Cleaved Bid provides an essential link between reovirus-induced death-receptor mediated caspase-8 activation and activa- tion of mitochondrial pathways. Inhibition of caspase-8 activation by over-expression of DN-FADD prevented Bid cleavage, suggesting that reovirus infection also activated the mitochondrial apoptotic pathway. Cytochrome $c$ was found to be present in the cytoplasm of infected cells at $\sim 10 \mathrm{~h}$ post infection. Additionally, cytochrome $c$ release was blocked in FADD-DN expressing cells suggesting that this event requires caspase-8. We also found that caspase9 is activated at $\sim 12 \mathrm{~h}$ post infection.

Having shown that reovirus infection was associated with activation of both death-receptor and mitochondrialassociated initiator caspases, we next wished to determine which effector caspases were subsequently activated. Here we show that the effector caspase, caspase- 3 is activated beginning at $\sim 8 \mathrm{~h}$ post infection and peaking at $\sim 18 \mathrm{~h}$ post infection. Additionally, caspase-7 was activated in reovirus-infected cells, although this event occurs later than caspase-3 activation. Another effector caspase, caspase-6, was not activated in reovirus-infected cells.

There is evidence that although mitochondrial cytochrome $c$ release and caspase- 9 activation occur downstream of death receptor stimulation, that these events are not necessarily required for all forms of death-receptor initiated apoptosis. ${ }^{19,20}$ Therefore we examined the effects of $\mathrm{Bcl}-2$ overexpression on effector caspase activation following reovirus infection. Bcl-2 overexpression inhibits the activation of both caspase- 3 and caspase-7, as well as the second phase of caspase- 8 activation. This data is consistent with earlier studies suggesting that reovirusinduced apoptosis could be inhibited in MDCK cells overexpressing $\mathrm{Bcl}-2 .^{2}$ This provides conclusive evidence of the importance of the mitochondrial apoptotic pathway in reovirus-induced cell death.

Caspases can be broadly grouped into three categories based on their pattern of substrate specificity. ${ }^{22,23} \mathrm{~A}$ group II caspase inhibitor completely blocked reovirus-induced caspase-3 activity at low concentrations. This result is consistent with the known activation of caspases-3 and -7 in reovirus infection. A group I caspase inhibitor had no effect, even at high concentrations. This suggested that caspases-1, -4 and -5 do not play a significant role in reovirus-induced apoptosis. A group III caspase inhibitor significantly reduced caspase- 3 activity, but its effect was only partial when compared to the group II inhibitor. This result was consistent with our observation that caspase-8 and -9 were involved in reovirus-induced caspase-3 activation. The lack of complete inhibition of caspase-3 activation by the group III inhibitor suggests that additional, as yet unidentified, caspases may also contribute to reovirus-induced caspase-3 activation. However, the complete inhibition of caspase-3 activation seen in cells expressing DN-FADD suggests that death receptor activation is the key initiating event in all reovirus-induced caspase activation cascades that ultimately contribute to effector caspase activation.

Our data provides the first comprehensive model of the events leading to apoptosis when cells are infected with a non-enveloped RNA virus whose replication cycle occurs entirely within the cytoplasm (Figure 8). Apoptosis is initiated through cell surface death receptors leading to 


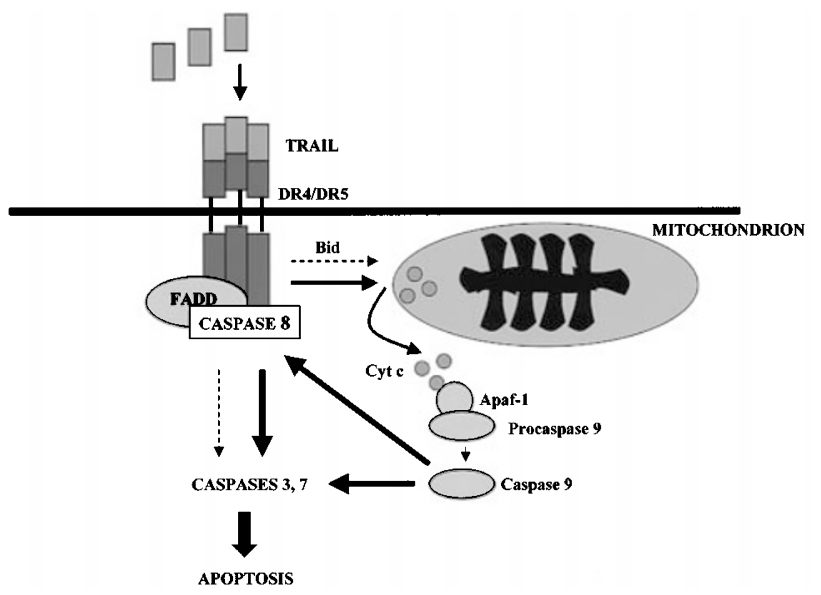

Figure 8 Schematic representation of reovirus-induced apoptosis pathways. Reovirus infection promotes release of cell-associated TRAIL and DR4/DR5dependent apoptosis. An early phase of caspase-8 activation leads to cleavage of Bid and low level activation of caspase-3 (dashed arrows). This is followed by a second phase of caspase activation in which release of cytochrome $c$ activates caspase-9 inducing further caspase-8 activation (solid arrows). Caspase- 8 and caspase- 9 contribute to effector caspase activation

the activation of caspase-8. Caspase-8 activation is essential for virus-induced apoptosis, and inhibition of this activation in cells stably expressing DN-FADD completely inhibits reovirus-induced effector caspase activation. Caspase- 8 activation results in cleavage of Bid and activation of mitochondrial apoptotic pathways. Activation of caspase8 in the absence of augmentation from the mitochondrial pathway, as occurs in cells stably expressing Bcl-2, results in only low levels of effector caspase activation. These results are consistent with the biphasic pattern of activation of caspase-8, Bid, and caspase-3. Early activation of caspase-8 and Bid induces the mitochondrial pathway which in turn amplifies caspase-8 and Bid activation allowing full expression of apoptosis.

\section{Materials and Methods}

\section{Reagents}

Anti-cytochrome $c(7 \mathrm{H} 8.2 \mathrm{C} 12)(1: 1000)$, anti-PARP (C2-10) (1:2000), anti-caspase-6 (B93-4) (1:1000), anti-caspase-8 (B9-2) $(1: 2000)$, and anti-caspase-9 $(1: 1000)$ antibodies were purchased from Pharmingen (San Diego, CA, USA). Anti-caspase-3 (1:1000) and anti-caspase-7 (1:1000) were purchased from Cell Signaling Technology (Beverly, MA, USA). Anti-Bid antibodies (1:1000) were from Trevigen (Gaithersburg, MD, USA). Anti-actin antibodies (JLA20) (1:5000) were from Calbiochem (Darmstadt, Germany). Anti-human cytochrome $c$ oxidase (subunit II) antibodies (12C4-F12) (1:1000) were from Molecular Probes (Eugene, OR, USA). Anti-Fas antibody $(\mathrm{CH}-11)$ was from Upstate Biotechnology (Lake Placid, NY, USA). Caspase synthetic peptide inhibitors used were caspase-3 Inhibitor I (cell permeable), caspase-8 Inhibitor I (cell permeable), and caspase1 Inhibitor I (cell permeable) (Calbiochem, Darmstadt, Germany). ApoAlert caspase-3 fluorometric assay kit was purchased from Clontech (Palo Alto, CA, USA).

\section{Cells, virus, and DNA constructs}

HEK293 cells (ATCC CRL1573) were grown in Dulbecco's modified Eagle's medium (DMEM) supplemented with $100 \mathrm{U} / \mathrm{ml}$ each of penicillin and streptomycin and containing $10 \%$ fetal bovine serum. Jurkat cells were a gift of Dr. John Cohen and were grown in RPMI supplemented with $100 \mathrm{U} / \mathrm{ml}$ each of penicillin and streptomycin and containing $10 \%$ fetal bovine serum. FADD-DN cells were a gift of Dr. Gary Johnson and express amino acids 80-208 of the FADD cDNA (with the addition of an AU1 epitope tag at the N-terminus) from the CMV promoter of pcDNA3 (Invitrogen, Carlsbad, CA, USA). HEK 293 cells stably over-expressing Bcl-2 were provided by Dr. Gary Johnson. The cell line was constructed by cloning full-length $\mathrm{Bcl}-2$ into the pLXSN vector and transfecting cells via retroviral transduction. Reovirus (Type 3 Abney, T3A) is a laboratory stock, which has been plaque purified and passaged (twice) in L929 cells (ATCC CCL1) to generate working stocks. ${ }^{40}$ All experiments were performed using an M.O.I. of 100. High M.O.I.s were chosen to insure synchronized infection of all susceptible cells, and to maximize the apoptotic stimulus.

\section{Western blot analysis}

Reovirus-infected cells were harvested at the indicated times, pelleted by centrifugation, washed with ice-cold phosphate-buffered saline, and lysed by sonication in $150 \mu$ l of lysis buffer ( $1 \% \mathrm{NP} 40,0.15 \mathrm{M}$ $\mathrm{NaCl}, 5.0 \mathrm{mM}$ EDTA, $0.01 \mathrm{M}$ Tris (pH 8.0), $1.0 \mathrm{mM} \mathrm{PMSF}, 0.02 \mathrm{mg} / \mathrm{ml}$ leupeptin, $0.02 \mathrm{mg} / \mathrm{ml}$ trypsin inhibitor). Lysates were cleared by centrifugation (20 $000 \times g, 2 \mathrm{~min}$ ), mixed 1:1 with SDS sample buffer, boiled for $5 \mathrm{~min}$, and stored at $-70^{\circ} \mathrm{C}$. To prepare mitochondrial-free extracts, cells were pelleted, washed twice in ice-cold PBS, and incubated on ice for $30 \mathrm{~min}$ in buffer containing $220 \mathrm{mM}$ mannitol, $68 \mathrm{mM}$ sucrose, $50 \mathrm{mM}$ PIPES-KOH (pH 7.4), $50 \mathrm{mM} \mathrm{KCl,} 5 \mathrm{mM}$ EGTA, $2 \mathrm{mM} \mathrm{MgCl}$, $1 \mathrm{mM}$ DTT, and protease inhibitors (complete cocktail, Boehringer Mannheim, Indianapolis, IN, USA). Cells were lysed using 40 strokes in a Dounce homogenizer (B pestle). Lysates were centrifuged at $14000 \times g$ for $15 \mathrm{~min}$ at $4^{\circ} \mathrm{C}$ to remove debris. Supernatants and mitochondrial pellets were prepared for electrophoresis as above. Proteins were separated by SDS-PAGE electrophoresis and transferred to Hybond-c extra nitrocellulose membrane (Amersham, Buckinghamshire, UK) for immunobloting. Blots were then probed with the specified antibodies at the dilutions described above. Proteins were visualized using the ECL detection system (Amersham, Buckinghamshire, UK). Densitometric analysis was performed using a FluorS Multilmager system and Quantity One software (Bio-Rad, Hercules, CA, USA).

\section{Caspase- 3 activation assays}

Caspase-3 activation assays were performed using a kit obtained from Clontech (Palo Alto, CA, USA). Experiments were performed using $1 \times 10^{6}$ cells/time point. Cells were centrifuged at $200 \times g$, supernatants were removed, and the cell pellets were frozen at $-70^{\circ} \mathrm{C}$ until all the time points were collected. Assays were performed in 96-well plates and analyzed using a fluorescent plate reader (CytoFluor 4000, PerSeptive Biosystems, Framingham, MA, USA). Cleavage of DEVD-AFC, a synthetic caspase-3 substrate, was used to determine caspase-3 activation. Cleavage after the second Asp residue produces free AFC. The amount of fluorescence detected is directly proportional to amount of caspase-3 activity. Because all of the fluorogenic substrate assay experiments were performed at the same time, both the mock and reovirus-induced caspase- 3 activation profiles are the same in all of these experiments and are included in each figure to facilitate comparisons. Results of all experiments are reported as means \pm S.E.M. 


\section{Acknowledgements}

This work was supported by Public Health Service grant 1RO1AG14071 from the National Institute of Aging, Merit and REAP grants from the Department of Veterans Affairs, and a US Army Medical Research and Material Command grant (DAMD179818614). Tissue culture media was obtained from the UCHSC Cancer Center Media Core.

\section{References}

1. Oberhaus SM, Dermody TS and Tyler KL (1998) Apoptosis and the cytopathic effects of reovirus. Curr. Top. Microbiol. Immunol. 233: 23-49

2. Rodgers SE, Barton ES, Oberhaus SM, Pike B, Gibson CA, Tyler KL and Dermody TS (1997) Reovirus-induced apoptosis of MDCK cells is not linked to viral yield and is blocked by Bcl-2. J. Virol. 71: 2540-2546

3. Tyler KL, Squier MK, Rodgers SE, Schneider BE, Oberhaus SM, Grdina TA, Cohen JJ and Dermody TS (1995) Differences in the capacity of reovirus strains to induce apoptosis are determined by the viral attachment protein sigma 1. J. Virol. 69: 6972-6979

4. Oberhaus SM, Smith RL, Clayton GH, Dermody TS and Tyler KL (1997)Reovirus infection and tissue injury in the mouse central nervous system are associated with apoptosis. J. Virol. 71: 2100-2106

5. DeBiasi RL, Edelstein CL, Sherry and Tyler KL (2001) Calpain inhibition protects against virus-induced apoptotic myocardial injury. J. Virol. 75: 351-361

6. Barton ES, Forrest JC, Connolly JL, Chappell JD, Liu Y, Schnell FJ, Nusrat A, Parkos CA and Dermody TS (2001) Junction adhesion molecule is a receptor for reovirus. Cell 104: $441-451$

7. Clarke P, Meintzer SM, Gibson S, Widmann C, Garrington TP, Johnson GL and Tyler KL (2000) Reovirus-induced apoptosis is mediated by TRAIL. J. Virol. 74: $8135-8139$

8. Ashkenazi A and Dixit VM (1998) Death receptors: signaling and modulation. Science 281: 1305-1308

9. Li P, Nijhawan D, Budihardjo I, Srinivasula SM, Ahmad M, Alnemri ES and Wang X (1997) Cytochrome $c$ and dATP-dependent formation of Apaf-1/caspase-9 complex initiates an apoptotic protease cascade. Cell 91: 479-489

10. Verhagen AM, Ekert PG, Pakusch M, Silke J, Connolly LM, Reid GE, Moritz RL, Simpson RJ and Vaux DL (2000) Identification of DIABLO, a mammalian protein that promotes apoptosis by binding to and antagonizing IAP proteins. Cell 102: $43-53$

11. Du C, Fang M, Li Y, Li L and Wang X (2000) Smac, a mitochondrial protein that promotes cytochrome c-dependent caspase activation by eliminating IAP inhibition. Cell 102: 33-42

12. Joza N, Susin SA, Daugas E, Stanford WL, Cho SK, Li CY, Sasaki T, Elia AJ, Cheng Hy, Ravagnan L, Ferri KF, Zamzami N, Wakeham A, Hakem R, YoshidaH Kong YY, MakTW, Zuniga-Pflucker JC, Kroemer G and Penninger JM (2001) Essential role of the mitochondrial apoptosis-inducing factor in programmed cell death. Nature 410: $549-554$

13. Zou H, Li Y, Liu X and Wang X (1999) An APAF-1-cytochrome c multimeric complex is a functional apoptosome that activates procaspase-9. J. Biol. Chem. 274: $11549-11556$

14. Gross A, Yin XM, Wang K, Wei MC, Jockel J, Milliman C, Erdjument-Bromage H, Tempst $P$ and Korsmeyer SJ (1999) Caspase cleaved BID targets mitochondria and is required for cytochrome $c$ release, while BCL-XL prevents this release but not tumor necrosis factor-R1/Fas death. J. Biol. Chem. 274: 1156-1163

15. LiH, Zhu H, Xu CJ and Yuan J (1998) Cleavage of BID by caspase 8 mediates the mitochondrial damage in the Fas pathway of apoptosis. Cell 94: 491-501

16. Luo X, Budihardjol, Zou H, Slaughter C and Wang X (1998) Bid, a Bcl2 interacting protein, mediates cytochrome $c$ release from mitochondria in response to activation of cell surface death receptors. Cell 94: 481-490

17. Yamada H, Tada-Oikawa S, Uchida A and Kawanishi S (1999) TRAIL causes cleavage of bid by caspase- 8 and loss of mitochondrial membrane potential resulting in apoptosis in BJAB cells. Biochem. Biophys. Res. Commun. 265: $130-133$

18. Yin XM, Wang K, Gross A, Zhao Y, Zinkel S, KlockeB, Roth KA and Korsmeyer SJ (1999) Bid-deficient mice are resistant to Fas-induced hepatocellular apoptosis. Nature 400: $886-891$
19. Scaffidi C, Schmitz I, Zha J, Korsmeyer SJ, Krammer PH and Peter ME (1999) Differential modulation of apoptosis sensitivity in CD95 type I and type II cells. J. Biol. Chem. 274: 22532-22538

20. Scaffidi C, Fulda S, Srinivasan A, Friesen C, Li F, Tomaselli K,J Debatin KM, Krammer PH and Peter ME (1998) Two CD95 (APO-1/Fas) signaling pathways. EMBO J. 17: $1675-1687$

21. Hu S, Vincenz C, Ni J, Gentz R and Dixit VM (1997) I-FLICE, a novel inhibitor of tumor necrosis factor receptor-1- and CD-95-induced apoptosis. J. Biol. Chem. 272: $17255-17257$

22. Thornberry NA, Rano TA, Peterson EP, Rasper DM, Timkey T, Garcia-Calvo M, Houtzager VM, Nordstrom PA, Roy S, Vaillancourt JP, Chapman KT and Nicholson DW (1997) A combinatorial approach defines specificities of members of the caspase family and granzyme B. Functional relationships established for key mediators of apoptosis. J. Biol. Chem. 272: 17907-17911

23.Talanian RV, Quinlan C, Trautz S, Hackett MC, Mankovich JA, Banach D, Ghayu T, Brady KD and Wong WW (1997) Substrate specificities of caspase family proteases. J. Biol. Chem. 272: 9677-9682

24. Nava VE, Rosen A, Veliuona MA, Clem RJ, Levine B and Hardwick JM (1998) Sindbis virus induces apoptosis through a caspase-dependent, CrmA-sensitive pathway. J. Virol. 72: 452-459

25. Jan JT, Chatterjee S and Griffin DE (2000) Sindbis virus entry into cells triggers apoptosis by activating sphingomyelinase, leading to the release of ceramide. $J$. Virol. 74: 6425-6432

26. Stewart SA, Poon B, Song JY and Chen IS (2000) Human immunodeficiency virus type $1 \mathrm{vpr}$ induces apoptosis through caspase activation. J. Virol. 74: 3105-3111

27. Biard-Piechaczyk M, Robert-Hebmann V, Richard V, Roland J, Hipskind RA and Devaux C (2000) Caspase-dependent apoptosis of cells expressing the chemokine receptor CXCR4 is induced by cell membrane-associated human immunodeficiency virus type 1 envelope glycoprotein (gp120). Virology 268: 329-344

28. Galvan V, Brandimarti R, Munger J and Roizman B (2000) Bcl-2 blocks a caspase-dependent pathway of apoptosis activated by herpes simplex virus 1 infection in HEp-2 cells. J. Virol. 74: 1931-1938

29. Takizawa T, Tatematsu C, Ohashi K and Nakanishi Y (1999) Recruitment of apoptotic cysteine proteases (caspases) in influenza virus-induced cell death. Microbiol. Immunol. 43: 245-252

30. Bitzer M, Prinz F, Bauer M, Spiegel M, NeubertWJ, Gregor M, Schulze-Osthoff K and Lauer U (1999) Sendai virus infection induces apoptosis through activation of caspase- 8 (FLICE) and caspase-3 (CPP32). J. Virol. 73: 702-708

31. Eleouet JF, Chilmonczyk S, Besnardeau L and Laude H (1998) Transmissible gastroenteritis coronavirus induces programmed cell death in infected cells through a caspase-dependent pathway. J. Virol. 72: 4918-4924

32. O'Brien V (1998) Viruses and apoptosis. J. Gen. Virol. 79: 1833-1845

33. Razvi ES, Welsh RM (1995) Apoptosis in viral infections. Adv. Virus Res. 45: 1 60

34. Teodoro JG and Branton PE (1997) Regulation of apoptosis by viral gene products. J. Virol. 71: $1739-1746$

35. Shen Y and Shenk TE (1995) Viruses and apoptosis. Curr. Opin. Genet. Dev. 5: $105-111$

36. Adams JM and Cory S (1998) The Bcl-2 protein family: arbiters of cell survival. Science 281: $1322-1326$

37. Reed JC (1998) Bcl-2 family proteins. Oncogene 17: 3225-3236

38. Ferri KF, Jacotot E, Blanco J, Este JA, Zamzami N, Susin SA, Xie Z, Brothers G, Reed JC, Penninger JM and Kroemer G (2000) Apoptosis control in syncytia induced by the HIV type 1-envelope glycoprotein complex: role of mitochondria and caspases. J. Exp. Med. 192: 1081-1092

39. Danen-van Oorschot AA, Der Eb AJ and Noteborn MH (2000) The chicken anemia virus-derived protein apoptin requires activation of caspases for induction of apoptosis in human tumor cells. J. Virol. 74: 7072-7078

40. Tyler KL, Squier MK, Brown AL, Pike B, Willis D, Oberhaus SM, Dermody TS and Cohen JJ (1996) Linkage between reovirus-induced apoptosis and inhibition of cellular DNA synthesis: role of the S1 and M2 genes. J. Virol. 70: 7984-7991 